\title{
An Adiabatic Saturation Psychrometer
}

\author{
Lewis Greenspan and Arnold Wexler
}

\author{
Institute for Basic Standards, National Bureau of Standards, Washington, D.C. 20234
}

(November 17, 1967)

\begin{abstract}
An adiabatic saturation psychrometer for measuring the humidity of gases, as well as the vapor content of vapor-gas mixtures, is described. The instrument behaves in accordance with predictions deduced solely from thermodynamic considerations. With water-air, water-hydrogen, carbon tetrachloride-hydrogen, carbon tetrachloride-oxygen and toluene-air systems, at room temperature, atmospheric pressure, and gas flow rates of 1.3 to 5.2 liters per minute, measured wet-bulb temperatures agree with calculated "thermodynamic wet-bulb temperatures" to within the accuracy of the measurements and the uncertainties in the published thermodynamic data used in the computations. For the water-air system, the systematic and random errors due to these sources are estimated at $0.027 \mathrm{deg} C$ and $0.019 \mathrm{deg} \mathrm{C}$ respectively. The agreement between the calculated and measured wet-bulb temperature is $0.029 \mathrm{deg} \mathrm{C}$, which at a dry-bulb temperature of $25^{\circ} \mathrm{C}$ and an ambient pressure of 1 bar is equivalent to an uncertainty in relative humidity which varies from $1 / 8$ to $1 / 4$ percent. The time constant is a function of the gas flow rate; at flow rates of 3.75 to 5.2 liters per minute, the time constant is of the order of $3 / 4$ minute.
\end{abstract}

Key Words: Adiabatic saturation, gas mixtures, humidity, hygrometer, mixing ratio, moist gas, psychrometer, psychrometric factor, saturation, thermodynamic wet-bulb temperature, vapor content, wet-bulb.

\section{Introduction}

The psychrometer is one of the oldest and most common instruments for measuring the humidity of moist air. In its elemental form it consists of two thermometers; the bulb of one is covered with a wick and is moistened; the bulb of the other is left bare and dry. Evaporation of water from the moistened wick lowers its temperature below the ambient or dry-bulb temperature. The wet-bulb temperature attained with the conventional psychrometer is dependent on many factors in addition to the moisture and temperature state of the gas [1-4]. ${ }^{1}$ Although attempts have been made to develop a theory that would correctly interrelate the parameters affecting the behavior of the conventional psychrometer, there is no theory which completely describes its performance. In the well-known convection or adiabatic saturation theory [5-10], the principles of classical thermodynamics exclusively are used to derive a formula that predicts the humidity of a moist gas from wet- and dry-bulb thermometer measurements. Unfortunately the conventional psychrometer, even under steady-state conditions, is an open system undergoing a nonequilibrium process which cannot be depicted completely by classical thermodynamic theory. It is fortuitous that the formulas so derived

${ }^{1}$ Figures in brackets indicate the literature references at the end of this paper. yield results that are in nominal agreement with empirical facts for water vapor-air mixtures. When these formulas are applied to other vapor-gas mixtures, they fail to predict the correct vapor content.

The wet-bulb thermometer of a psychrometer in a steady-state condition experiences simultaneous heat and mass transfer. Although theories based on heat and mass transfer laws lead to equations which have a structural similarity to those derived from thermodynamic reasoning as well as to those of empirical origin, they also involve the ratio of thermal to mass diffusivities [3, 11-21]. Even these equations, which yield results in closer agreement with experimental data, do not completely depict all psychrometric behavior. For the water-air system, the ratio of thermal to mass diffusivity is close to one, accounting, in part, for the nominal agreement between the predictions based on the convection theory with those based on heat and mass transfer laws. In general, this ratio is greater than one [11, 22].

It would be advantageous to have an adequate theoretical basis for the behavior of the conventional psychrometer, but lacking a rational theory which accurately and fully describes the operation of the conventional psychrometer, one can invert the problem and inquire whether a psychrometer can be built which will behave in accordance with the postulates of classical thermodynamics. It appears that such a psychrometer can be designed and constructed and 
that its behavior can be predicted by thermodynamic reasoning and expressed in mathematical form.

\section{Theoretical Considerations}

Consider a closed system undergoing an isobaric quasi-static process in which compressed liquid (or solid) at pressure $P$ and temperature $T_{w}$ is introduced into a gas at pressure $P$, temperature $T$, and mixing ratio ${ }^{2} r$ to bring the gas adiabatically to saturation at pressure $P$, temperature $T_{w}$, and mixing ratio $r_{w}$. The term "gas" as used here and elsewhere in this paper is intended to include a gaseous mixture of which one constituent or component is a permanent gas or mixture of permanent gases and the second constitutent or component is the vapor of the compressed liquid involved in the psychrometric process and manifests itself as a product of evaporation. Since the process is adiabatic and isobaric the sum of the enthalpies of the various phases within the system are conserved, thus the initial and final enthalpies are equal, leading to the following equation:

$h(P, T, r)=h\left(P, T_{w}, r_{w}\right)-\left(r_{w}-r\right) \cdot h_{w}^{\prime}\left(P, T_{w}\right)$

where

$h(P, T, r)=$ The enthalpy of $(1+r) \mathrm{g}$ of gas mixture at pressure $P$, temperature $T$ and mixing ratio $r$, that is, the enthalpy of a mixture consisting on $1 \mathrm{~g}$ of the vapor-free gas and $r \mathrm{~g}$ of the vapor component;

$r=$ the mass of vapor in the original gas mixture per unit mass of vapor-free gas with which the vapor is associated;
$h_{w}^{\prime}\left(P, T_{w}\right)=$ the enthalpy of $1 \mathrm{~g}$ of pure compressed liquid (or solid) of the vapor component at pressure $P$ and temperature $T_{w}$;

$h\left(P, T_{w}, r_{w}\right)=$ the enthalpy of $\left(1+r_{w}\right)$ g of gas mixture saturated with respect to the second or vapor component at pressure $P$ and saturation temperature $T_{w}$, that is, the enthalpy of a gas mixture containing one gram of vapor-free gas and $r_{w} \mathrm{~g}$ of the vapor component; and

$r_{w}=r_{w}\left(P, T_{w}\right)=$ the mass of vapor component of the gas mixture per unit mass of vaporfree gas of the mixture when it is saturated with respect to the vapor component at pressure $P$ and temperature $T_{w}$.

The "thermodynamic wet-bulb temperature" is defined [23] as the solution for $T_{w}$ in eq (1).

In order to facilitate the mathematical development we introduce the following additional notation:

$\Delta T=\left(T-T_{w}\right)=$ The wet-bulb depression;

$h\left(P, T_{w}, r\right)=$ the enthalpy of $(1+r) \mathrm{g}$ of gas mixture at pressure $P$, temperature $T_{w}$ (the same as the "thermodynamic wet-bulb temperature" of the original gas mixture), and mixing ratio $r$ (the same as the mixing ratio of the original gas mixture);

$h(P, T, 0)=h(P, T, r=0)=$ the enthalpy of $1 \mathrm{~g}$ of the pure first (vapor-free) component of the mixture at pressure $P$ and temperature $T$; and

$h\left(P, T_{w}, 0\right)=h\left(P, T_{w}, r=0\right)=$ the enthalpy of $1 \mathrm{~g}$ of the pure first component of the mixture at pressure $P$ and temperature $T_{w}$.

${ }^{2}$ In several of the engineering disciplines $r$ is called the humidity ratio.

Let

$$
F=F\left(P, T, T_{w}, r\right)=\left[h(P, T, r)-h\left(P, T_{w}, r\right)\right]
$$

and

$$
C_{p, m}=\frac{\left[h(P, T, 0)-h\left(P, T_{w}, 0\right)\right]}{\left(T-T_{w}\right)}=\frac{1}{\left(T-T_{w}\right)} \int_{T_{w}}^{T} C_{p} d T
$$

where

$$
C_{p}=\text { the specific heat at constant pressure of the pure vapor-free component. }
$$

Also let

$$
C_{p v, m}=\frac{\left[h(P, T, r)-h\left(P, T_{w}, r\right)\right]-\left[h(P, T, 0)-h\left(P, T_{w}, 0\right)\right]}{r\left(T-T_{w}\right)}
$$

and

$$
L_{v, r}=\frac{\left[h\left(P, T_{w}, r_{w}\right)-h\left(P, T_{w}, r\right)-\left(r_{w}-r\right) h_{w}^{\prime}\left(P, T_{w}\right)\right]}{\left(r_{w}-r\right)}
$$


From the above definition, it will be clear that $C_{p, m}$ represents the mean specific heat at constant pressure of the pure vapor-free first component over the temperature range from $T_{w}$ to $T$. The entity $C_{p v, m}$ may be interpreted as the "effective" specific heat at constant pressure $P$ of the vapor component of the mixture taken as a mean over a temperature range from $T_{w}$ to $T$ and at a mixing ratio of $r$. Finally, $L_{v}, r$ may be understood as the "effective" latent heat of vaporization (or sublimation) of the vapor component of the mixture at constant pressure $P$ and constant temperature $T_{w}$. It will be seen that $L_{v, r}$ is taken as a mean while $\left(r_{w}-r\right)$ gram of vapor component evaporates into the gas mixture from a plane surface of its liquid phase per gram of first component. Both mixture and liquid must be at the same pressure $P$ and temperature $T_{w}$, the gas mixture having a mixing ratio $r$ initially and attaining a mixing ratio $r_{w}$ finally as a result of the process of evaporation.

It should be noted that the "effective" specific heat $C_{p v, m}$ and the "effective" latent heat of vaporization $L_{v, r}$ both differ from their counterparts pertinent to the pure phase of the second (vapor) component owing to the interactions between the molecules of the first and second components of the gas mixture, and due to other small effects [24].

By adding to the function $F$ each of the quantities $h(P, T, 0)$ and $h\left(P, T_{w}, 0\right)$, both with positive and negative signs, respectively, one obtains the useful identity

$$
\begin{aligned}
& F=\left[h(P, T, r)-h\left(P, T_{w}, r\right)\right] \\
& =[h(P, T, r)-h(P, T, 0)]-\left[h\left(P, T_{w}, r\right)-h\left(P, T_{w}, 0\right)\right] \\
& +\left[h(P, T, 0)-h\left(P, T_{w}, 0\right)\right] .
\end{aligned}
$$

When one subtracts $h\left(P, T_{w}, r\right)$ from both the left-hand and right-hand members of eq (1), it is obvious that the left-hand member transforms to the function $F$. Therefore, the right-hand member of eq (1) minus $h\left(P, T_{w}, r\right)$ is also equal to $F$, so that we can equate this difference to eq (6) which yields the relationship

$$
\begin{aligned}
{\left[h\left(P, T_{w}, r_{w}\right)-\right.} & \left.h\left(P, T_{w}, r\right)\right]-\left(r_{w}-r\right) h_{w}^{\prime}\left(P, T_{w}\right) \\
= & {[h(P, T, r)-h(P, T, 0)] } \\
- & {\left[h\left(P, T_{w}, r\right)-h\left(P, T_{w}, 0\right)\right] } \\
& \quad+\left[h(P, T, 0)-h\left(P, T_{w}, 0\right)\right] .
\end{aligned}
$$

Inspection reveals that the product $\left(r_{w}-r\right) L_{v, r}$ is equal to the left-hand member of eq (7), while the sum of the products $\left(T-T_{w}\right) C_{p, m}$ and $r\left(T-T_{w}\right) C_{p v, m}$ is equal to the right-hand member of eq (7). On making these substitutions in eq (7) it transforms to

$$
\left(r_{w}-r\right) L_{v, r}=\left[C_{p, m}+r C_{p v, m}\right]\left(T-T_{w}\right) .
$$

On introducing the "psychrometric factor" $A$ and the ratio $B$ defined by

$$
A=C_{p, m} / L_{v, r}
$$

$$
B=C_{p v, m} / L_{v, r}
$$

substituting these in eq (8), and solving it for $r$, one finds

$$
r=\frac{r_{w}}{[1+B \Delta T]}-\frac{A \Delta T}{[1+B \Delta T]}
$$

where $\Delta T=T-T_{w}$.

Solving eq (11) for $A$ one obtains

$$
A=\frac{r_{w}-r[1+B \Delta T]}{\Delta T} .
$$

The "psychrometric factor" $A$ as defined by eq (9) is identically equal to the "psychrometric factor" $A$ as given by eq (12).

For the case where the initial mixing ratio of the gas is zero, eq (12) reduces to

$$
A=\frac{r_{w}}{\Delta T}
$$

If the vapor and the gas separately and admixed with one another obey the ideal gas laws, eq (11) becomes

$$
r=\frac{r_{w}}{\left(1+B^{\prime} \Delta T\right)}-\frac{A^{\prime} \Delta T}{\left(1+B^{\prime} \Delta T\right)}
$$

or, alternately, in terms of vapor pressure,

$$
e=\frac{e_{w}}{\left(1+B^{\prime} \Delta T\right)} \frac{(P-e)}{\left(P-e_{w}\right)}-\frac{(P-e) A_{0} \Delta T}{\left(1+B^{\prime} \Delta T\right)}
$$

where

$$
\begin{gathered}
A_{0}=\frac{M_{g}}{M_{v}} \frac{C_{p}^{\prime}}{L_{v}^{\prime}} \\
A^{\prime}=\frac{C_{p}^{\prime}}{L_{v}^{\prime}} \\
B^{\prime}=\frac{C_{p v}^{\prime}}{L_{v}^{\prime}}
\end{gathered}
$$

and

$e=$ the partial pressure of the vapor component in the original gas mixture;

$e_{w}=$ the saturation vapor pressure of the liquid phase of the vapor component at temperature $T_{w}$;

$P=$ the total pressure;

$C_{p v}^{\prime}=$ the pure phase specific heat of the vapor at constant pressure;

$L_{v}^{\prime}=$ the pure phase latent heat of vaporization of the vapor;

$C_{p}^{\prime}=$ the specific heat of the vapor-free gas at constant pressure; 
$A_{0}=$ the so-called "psychrometric constant" (which appears in most formulas for the conventional psychrometer [3]);

$M_{g}=$ the molecular weight of the vapor-free gas component; and

$M_{r}=$ the molecular weight of the vapor component.

When $e$ and $e_{u}$ are small compared to $P$ and $B^{\prime} \Delta T$ is small compared to one, which is the case for the waterair system at dry-bulb temperatures $T$ up to about 45 ${ }^{\circ} \mathrm{C}$, eq (15) reduces to

$$
e=e_{w}-A_{0} P \Delta T
$$

which is identical to the classical equation often used to represent the behavior of the conventional psychrometer.

It does not appear feasible to construct a practical psychrometer that is an embodiment of a closed system undergoing the ideal adiabatic isobaric saturation process which serves as the basis of eq (1). On the other hand, an open system undergoing a steady-flow process would appear to be operationally feasible, and such a system was constructed and its performance investigated. The aim was to approach ideal conditions as closely as practical, namely to bring compressed liquid (or solid) to pressure $P$ and temperature $T_{w}$, to evaporate it into a gas stream at pressure $P$, temperature $T$ and mixing ratio $r$, and to bring the gas adiabatically to saturation at pressure $P$, temperature $T_{w}$, and mixing ratio $r_{w}$. This system then becomes an adiabatic saturator operating at constant pressure. If nothing enters to violate the conditions of eq (1), the adiabatic saturator becomes an "adiabatic saturation psychrometer" since measured values of $P, T$, and $T_{w}$ can be inserted into eq (11) to obtain the mixing ratio of the entrant gas stream. It was realized that practical and theoretical matters, such as heat exchanges due to radiation and conduction, and pressure drop associated with flow, would be among the factors limiting the possibility of attaining the ideal, especially in view of the desire to keep the apparatus simple for ease of construction. It was left, therefore, to experiment to serve as the indicator of how close the actual psychrometer conformed to theory.

\section{Background}

In 1922, W. K. Lewis performed several experiments in which a dried gas was bubbled through a volatile liquid in a Dewar flask containing glass beads, the gas being discharged into the liquid through a vacuumjacketed glass inlet tube. For water-air, water-carbon dioxide, toluol-air and chlorbenzol-air the gas substantially became saturated and the liquid (as well as the effluent gas) eventually reached a steady-state temperature that was essentially the "thermodynamic wet-bulb temperature." The readings of wet-bulb temperature in the experiments using water, toluol and chlorbenzol as the liquid were independent of air velocity and of the amount of air contact with the liquid. This was not the case in the experiments with liquids of higher vapor pressure. The discrepancy probably was due to incomplete saturation and incomplete heat transfer between the gas and liquid rather than lack of constancy of the wet-bulb temperature as Lewis assumed.

Nanda and Kapur [28] performed similar experiments, bubbling dried air into a Dewar containing such liquids as acetone, methyl alcohol, ethyl alcohol, and butyl alcohol. After a considerable length of time, the liquid temperature approached the "thermodynamic wet-bulb temperature."

We also repeated these experiments, and in doing so found it necessary to use a vacuum-jacketed glass inlet tube, such as Lewis had used, for bubbling the gas through the liquid in the Dewar flask. With this inlet tube, which reduced precooling of the inlet gas prior to discharge into the liquid, steady-state temperatures of the liquids were obtained, which were in close agreement with calculated "thermodynamic wet-bulb temperatures," provided the gas flow was very low and only after extended continuous flow, usually hours.

Although "thermodynamic wet-bulb temperatures" could be obtained with the Dewar flask, the low gas flow rates, and the extremely long time necessary to reach steady-state conditions at these flow rates, seemed to preclude its use as a practical instrument for measuring humidity.

Carrier and Lindsay [25], and Dropkin [14] constructed large scale, engineering-type apparatus for obtaining adiabatic saturation. The essential feature of these devices was the provision for passing air over surfaces moistened with water that had been precooled to, or close to, the wet-bulb temperature, within well-insulated ducts. The experiments performed by these investigators were limited to the water-air system.

In 1961, J. D. Wentzel described a psychrometer which apparently measured the "thermodynamic wet-bulb temperature" of water-air with high accuracy [29]. In his instrument, Wentzel attempted to saturate adiabatically a stream of test air (whose humidity was to be measured) with water vapor in a fashion that appeared to approach the idealized steadyflow adiabatic process. Basically his instrument consisted of a vacuum-insulated glass tube, the inner walls of which were silvered to reduce radiation effects. The tube was partially filled with a moistened natural sponge through which the air flowed. Makeup water was added intermittantly, in one design, and continuously in a second design. In the latter version, the continuous flow of makeup water was precooled by an essentially equivalent instrument through which part of the gas stream was channeled. To preclude the possibility of drying of the sponge, excess makeup liquid was used. Wet-bulb temperatures were measured with thermocouples imbedded in the moistened sponge. Wet-bulb temperature measurements for the water-air system corresponded very closely to "thermodynamic wet-bulb temperatures." It is well known, however, that the wet-bulb temperature for moist air as measured with a conventional psychrom- 
eter nominally is not very different from the "thermodynamic wet-bulb temperature" so that further demonstration is required to establish that a psychrometer is undergoing a true thermodynamic wetbulb process. This could have been accomplished by the use of liquid-gas systems other than water-air for which the wet-bulb temperature as indicated by a conventional psychrometer, and the "thermodynamic wet-bulb temperature" differ appreciably.

L. P. Harrison [26] has proposed three psychrometer designs for measuring "thermodynamic wet-bulb temperature," each design involving the employment of three concentric tubes so arranged as to insure intimate contact between gas and liquid and therefore to insure adiabatic saturation.

We first duplicated Wentzel's instrument with some modifications. Whereas Wentzel successfully had employed natural sponges as his saturating element, we were unsuccessful in the use not only of natural but also of artificial sponges because of the tendency for the liquid to be blown out by the gas stream. Only when we finally resorted to cotton cheesecloth did the instrument operate satisfactorily. Various liquid-gas systems were tried and although wet-bulb temperatures approaching "thermodynamic wet-bulb temperatures" were obtained, these were not sufficiently close to one another to form the basis of an accurate measuring system. The best results were achieved with the water-air system. The major defect in the instrument appeared to be the lack of sufficient precooling of the liquid so that it would feed into the saturating element at, or very close to, the "thermodynamic wet-bulb temperature." With the water-air system the operation of an adiabatic saturation psychrometer is less sensitive to the liquid feed temperature than it is with some other liquid-gas systems.

We then developed an instrument utilizing vacuumjacketed glass tubes, as in the Wentzel instrument, but employing a different saturating element and a novel feed arrangement that precools the liquid very close to the wet-bulb temperature. "Thermodynamic wet- bulb temperatures" were closely approached with various liquid-gas systems, as well as with water-air.

\section{Description}

The instrument is shown in figures 1 and 2 . It consists of a vacuum-jacketed glass saturator tube, A, that is surrounded by a glass Dewar flask, B. Within the saturator tube is a thermocouple, $\mathrm{C}$, for measuring dry-bulb temperature, wicking, D, for saturating the gas stream, and a feed tube, E, through which liquid is introduced for moistening the wicking. A thermocouple, F, for measuring wet-bulb temperature is located beyond the outlet end of the saturator tube. The saturator tube is centered and held in the Dewar flask by a stopper, G. There is a pressure tap, H, at the outlet end of the saturator tube and an exit flow line, I, through which the effluent gas leaves the instrument. The test gas enters at the inlet end of the saturator tube, flows through the saturator tube, emerges at the outlet end of the saturator tube, reverses direction, flows over the exterior surface of the saturator tube and discharges through the exit flow line and micrometer valve, J.

The main component is the saturator tube fabricated with double walls, with the space between the walls evacuated and sealed. The tube is silvered to reduce radiation effects, is 13 in long, and has an o.d. of $1 / 2$ in and an i.d. of 0.15 in. It is within this saturator tube that the "thermodynamic wet-bulb process" occurs.

The liquid feed system comprises a graduated reservoir, $\mathrm{K}$, a preliminary heat exchanger, $\mathrm{L}$, a main heat exchanger, M, and a feed tube, E. Liquid flows from the reservoir, through the heat exchangers, the feed tube, and onto the wicking. The reservoir is mounted on a vertical rod. Its elevation can be adjusted to provide the required head of liquid to maintain the flow necessary for complete and continuous moistening of the wicking. The preliminary heat exchanger is a $12-\mathrm{ft}$

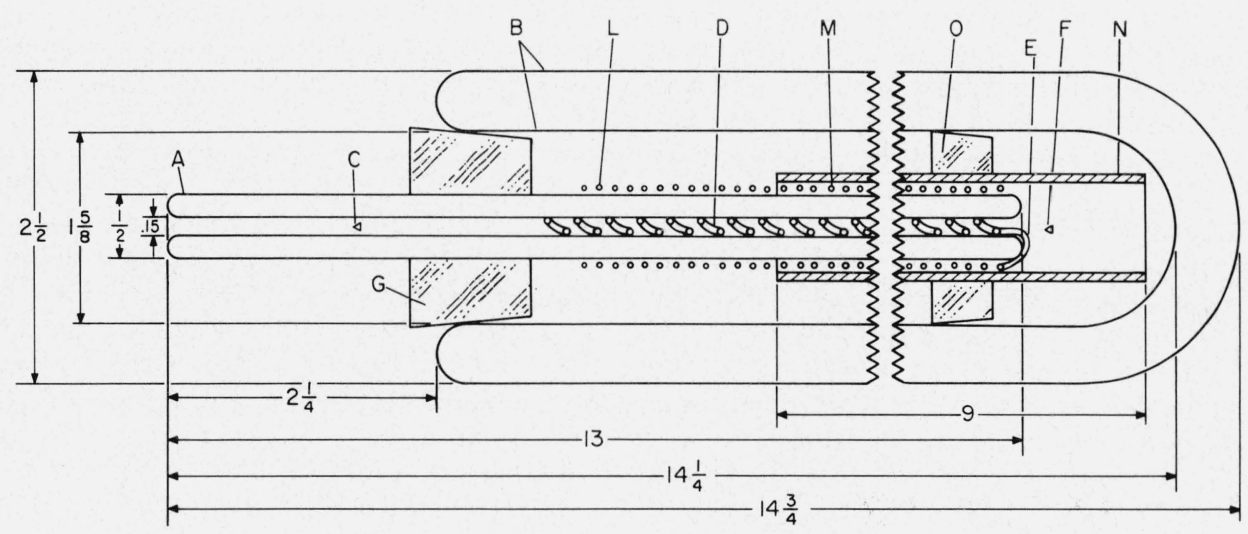

DIMENSIONS IN INCHES

FIGURE 1. Adiabatic psychrometer-principal section

A. Vacuum-jacketed glass saturator tube; B. glass Dewar flask; C. Dry-bulb thermocouple; D. Cotton wicking; E. liquid feed tube; F. wet-bulb thermocouple; G. saturator tube rubber stopper; L. preliminary heat exchanger; M. main heat exchanger; N. flow guide; O. flow guide cork stopper. 


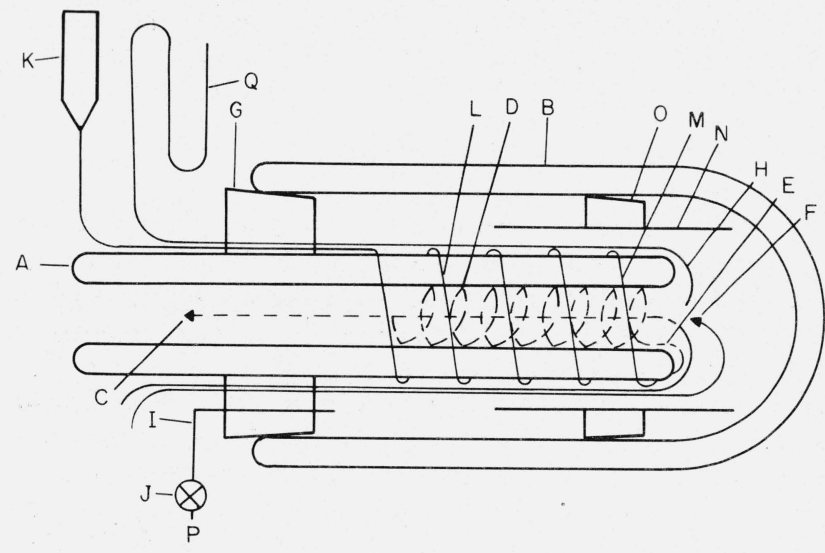

Figure 2. Adiabatic psychrometer-schematic A. Vacuum-jacketed glass saturator tube; B. glass Dewar flask; C. dry-bulb thermocouple; D. cottom wicking; E. liquid feed tube; F. wet-bulb thermocouple; G. saturator tube rubber stopper; H. static pressure tap; I. exit flow line; J. micrometer exhaust valve; K. graduated reservoir; L. preliminary heat exchanger; M. main heat exchanger; N. flow guide; $O$. flow guide cork stopper; $P$. vacuum source; $Q$. oil manometer.

length of polytetra fluoroethylene tubing, with an o.d. of about 0.045 in and an i.d. of about 0.021 in, loosely wound for 6 in around the outside of the saturator tube, connected at one end to the reservoir and at the other end to the main heat exchanger. The latter is a $5-\mathrm{ft}$ length of stainless steel tubing, with an o.d. of 0.0355 in and an i.d. of 0.023 in, wound into a $5 / 8$-in diam helix that fits over the outlet end of the saturator tube for a distance of $4 \mathrm{in}$. The feed tube is fabricated from $2 \mathrm{ft}$ of the same PTFE tubing as used in the preliminary heat exchanger. It is wound into a helix which fits inside the saturator tube and extends inward for 10 in from the outlet end.

The feed tube is covered with a close-fitting sleeve of cotton wicking. One end of the sleeve terminates $1 / 2$ in inside the outlet end of the saturator tube; the other end is tied tightly with cotton thread immediately beyond the discharge port of the feed tube.

The wet- and dry-bulb thermocouples are made from calibrated No. 40 copper and constantan wires encased in PTFE tubing like that described above. The dry-bulb thermocouple junction is located $1 \frac{1}{2} 2$ in inside the inlet end of the saturator tube and upstream of the wicking; the wet-bulb thermocouple junction is located just beyond the outlet end of the saturator tube downstream of the wicking. Both junctions are placed along the axis of the saturator tube.

A silvered glass Dewar flask, 12 in long and with an i.d. of $1 \frac{5}{8}$ in, encloses most of the saturator tube. The saturator tube fits tightly within a concentric hole in a No. 9 rubber stopper which, in turn, fits snugly into the mouth of the Dewar flask. The two sets of thermocouple wires, the preliminary heat exhanger, the pressure line, and the exit gas flow line are fed separately through, and tightly fitted in, holes in the stopper.

Within the Dewar flask is a glass tube, N, 9 inches in length, 7/8-in o.d., and 1/16-in thick, that is, in turn, supported by a cork stopper, 0 . The saturator tube with its associated components is positioned concentrically inside the glass tube. The latter serves as a flow guide for channeling the gas over the surface of the main heat exchanger. It reduces the size of the annulus through which the gas flows and improves the heat transfer between the liquid in the main heat exchanger and the gas.

The exit flow line is connected to a micrometer valve and then to a vacuum source, $P$. The pressure line is connected to an oil manometer, $Q$, which, in conjunction with a barometer which measures ambient atmospheric pressure, yields the absolute pressure at the outlet end of the saturator tube. A potentiometer and null detector are used to measure the emfs generated by the thermocouples. The saturator assembly is maintained in a horizontal orientation.

The saturator tube is constructed with a vacuum jacket to reduce heat transfer between its interior and its surroundings. The outer Dewar flask serves the purpose of providing additional thermal insulation from the ambient atmosphere for the test gas. The design of the liquid-feed tube and wicking combination is intended to provide a large evaporative area to the flowing gas while reducing as far as practical the pressure drop and total liquid heat capacity. The liquidfeed heat exchanger provides for the automatic precooling of the liquid by the gas which has been brought to the wet-bulb temperature by the moistened wicking. Counter flow of gas and liquid is used to obtain the maximum heat exchange. It was intended that the total heat capacity of the heat exchanger and its contained liquid should be as small as possible. The preliminary liquid-feed heat exhanger is not considered to be part of the thermal capacity of the main heat exchanger and is a slight embellishment for heat exchange purposes. The liquid reservoir height adjustment is used to control the rate of liquid feed. Both thermocouples were located so as to be exposed only to and in contact with the gas stream.

\section{Operating Procedure}

The instrument is operated by establishing a continuous flow of sample gas and liquid. After steadystate conditions are reached, the wet- and dry-bulb temperatures and the pressure are measured.

The test gas is fed to the saturator tube at atmospheric pressure. Because of the use of glass in the construction of the saturator tube and the Dewar flask and the use of stoppers for assembling and sealing these components, the maximum pressure within the psychrometer is limited to about $1 \mathrm{~atm}$. The outlet port of the micrometer valve is attached to a vacuum source. The micrometer valve is calibrated in terms of air flow over the range 0 to 6.2 liters per minute. By means of a density correction, the equivalent flow is obtained for any other gas. Thus, by an appropriate micrometer setting any desired flow within this range can be established through the psychrometer. Since the valve functions as a variable critical flow orifice, the volumetric flow through the psychrometer, for a given micrometer setting, is essentially constant.

The height of the reservoir is set so as to produce a liquid flow rate that is approximately three times that 
required to completely saturate the vapor-free test gas. This liquid flow rate is measured by timing the change in volume of the liquid in the graduated reservoir. If drying occurs in any part of the wicking, a temperature transient is propagated through the saturator that upsets the thermal equilibrium of the instrument and yields an erroneous wet-bulb temperature. Excess liquid insures that the wicking is always completely moistened; the excess is carried through the saturator by the flow of gas and collects in the Dewar flask where it can be drained manually or automatically. Since the liquid enters and emerges from the saturator tube at essentially wet-bulb temperature, the enthalpies of the excess liquid flowing into and out of the saturator are essentially equal and therefore do not contribute to the overall enthalpy balance as given in eq (1).

\subsection{Tests}

Since eq (1) represents an interrelation among parameters $P, T, T_{w}$, and $r$ such that $f\left(P, T, T_{u}, r\right)=0$, then if any three parameters, say $P, T$, and $r$ are measured and inserted into the equation, the fourth, $T_{w}$, can be calculated. If, in addition, a measurement is also made of $T_{u}$, the calculated and observed "thermodynamic wet-bulb temperatures" can be compared. Such a comparison offers a measure of the conformance of psychrometer behavior with theory.

Equation (12) may be expressed in the form

$$
\frac{C_{p, m}}{L_{\iota, r}}=\frac{r_{u}-r[1+B \Delta T]}{\Delta T}
$$

in which the right- and left-hand sides are different functions of the same parameters, that is,

$$
A_{1}\left(P, T, T_{u}, r\right)=A_{2}\left(P, T, T T_{u}, r\right) .
$$

By inserting the same set of measurements of the parameters $\left(P, T, T_{u}, r\right)$ into $A_{1}$ and $A_{2}$ these two functions can be calculated and compared. Such a comparison offers an alternate method of checking whether the psychrometer performs in accordance with theory. It should be recognized that $A_{1}$ and $A_{2}$ are alternate expressions of the "psychrometric factor."

A series of experiments was performed with the psychrometer, with various liquid-gas systems, to obtain experimental or observed values of the wetbulb temperature which is given the notation $\left(T_{u}\right)_{\text {obs }}$. With the same values of parameters $P, T$, and $r$, the "thermodynamic wet-bulb temperature", was calculated. To differentiate it from the observed value it is given the notation $\left(T_{u}\right)_{\text {calc. }}$ Because of the difficulty of generating vapor-gas mixtures of known mixing ratios to supply to the psychrometer, only dry, vaporfree gases were used. Thus, in each case the mixing ratio $r$ of the gas was zero. All experiments were performed at room temperature (about $25^{\circ} \mathrm{C}$ ), except for four test points with water-air which were performed at about $37^{\circ} \mathrm{C}$, and at atmospheric pressure (about 1 bar). The flow rate of the test gas mixture was varied over the range 0.8 to 6.2 liters per minute. The pos- sible implications due to the restriction $r=0$ will be discussed later.

The following systems were selected for the experiments: water-air, water-hydrogen, carbon tetrachlorideoxygen, carbon tetrachloride-hydrogen, and tolueneair. The gases were obtained from a commercial source in steel cylinders compressed to a pressure of about $120 \mathrm{~atm}$. The carbon tetrachloride was of spectro grade, the toluene of reagent grade, and the water of distilled grade purity. These systems encompass a range of thermal to mass diffusivity ratios of 0.9 to 4.5 as shown in table 5 .

The experimental setup is shown in figure 3 . The gas from a cylinder, $\mathrm{R}$, was passed through a high pressure reducer, $\mathrm{S}$, and a low pressure reducer, T, in series, a drier filled with phosphorous pentoxide, $\mathrm{U}$, and a stainless steel heat exchanger, $\mathrm{V}$, immersed in a temperature-controlled liquid bath, W, and then fed into the psychrometer, $X$, at a pressure of about $1 \mathrm{~atm}$. The desired gas flow rate was obtained by the appropriate setting of the micrometer on the exhaust valve, J. The reservoir, K, was filled with the test liquid and its elevation adjusted so that the liquid flow rate was approximately three times as great as that calculated as necessary to completely saturate the test gas at the wet-bulb temperature.

Tests were also performed to determine the speed of response of the instrument. Using air as the sample gas, and water as the liquid, the psychrometer was subjected to a nominal step-function change in mixing ratio at a dry-bulb temperature of $25^{\circ} \mathrm{C}$ and at an ambient atmospheric pressure of about 1 bar. Dry air was fed to the psychrometer. After steady-state conditions were reached, the connection feeding the dry air to the inlet of the saturator tube was quickly removed and ambient (room) air was drawn in producing an increase in mixing ratio. The procedure was then reversed producing a decrease in mixing ratio. The emf from the wet-bulb thermocouple was fed to a precision potentiometer. The unbalance of the potentiometer was amplified and recorded as a function of time. After nulling the potentiometer for the steadystate initial wet-bulb temperature condition, a trace was obtained of the wet-bulb temperature change produced by the step-function change in mixing ratio.

\subsection{Results}

A comparison is shown in table 1 between the observed and calculated "thermodynamic wet-bulb temperatures," $\left(T_{w}\right)_{\mathrm{obs}}$ and $\left(T_{w}\right)_{\text {calc }}$, for the several liquid-gas systems that were investigated. The absolute pressures $P$ in the region of the wet-bulb thermocouple are given in column 1. Column 2 lists the approximate flow rates of the gas at the inlet end of the psychrometer, that is, at temperature $T$. Columns 3 and 4 list the observed (measured) dry- and wet-bulb temperatures. The calculated wet-bulb temperatures, obtained by solving eq (23) or (24) (see appendix) for $T_{u}$, are given in column 5 . The differences between the observed and calculated wet-bulb temperatures, $\left[\left(T_{u}\right)_{\text {obs }}-\left(T_{u}\right)_{\text {calc }} \mid\right.$, are tabulated in column 6 . 


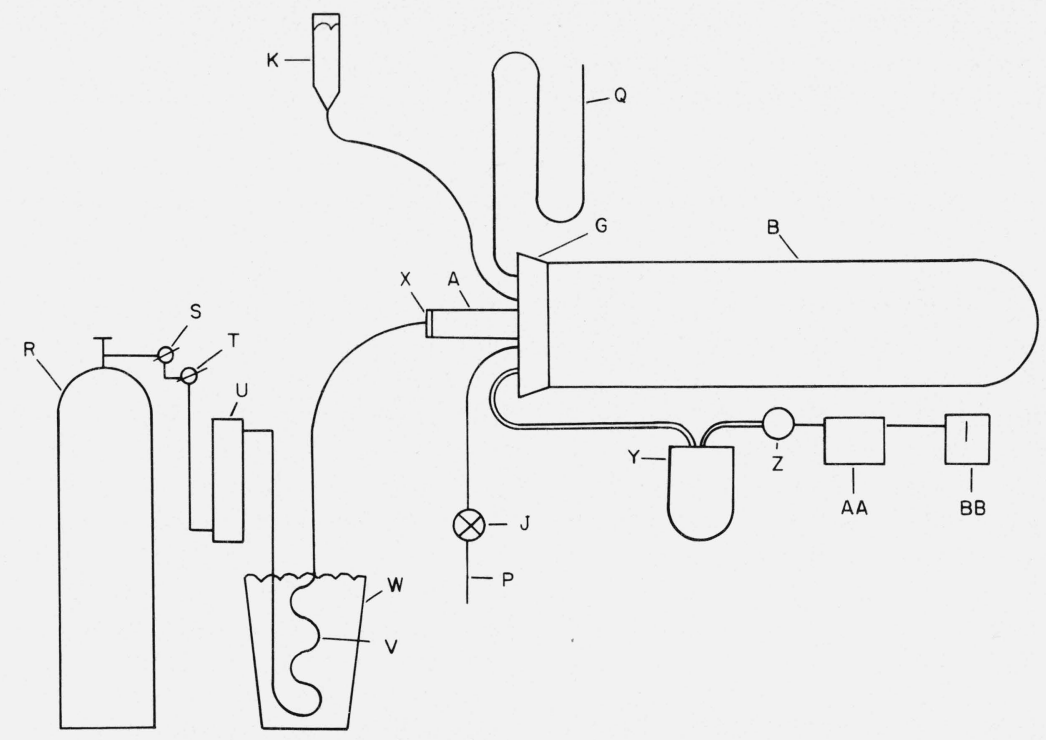

Figure 3. Test setup-schematic

J. micrometer exhaust valve; K. graduated reservoir; P. vacuum source; Q. oil manometer; R. compressed gas cylinder; S. high pressure reducer; T. low pressure reducer; U. drier; V. heat exchanger; W. temperature-controlled liquid bath; X. psychrometer; Y. reference junction ice bath; Z. thermocouple selector switch; AA. precison laboratory potentiometer; BB. null indicator.

Columns 7 and 8 of table 1 give values of the "psychrometric factor" $A_{2}=\frac{r_{w}}{\Delta T}$ and $A_{1}=\frac{C_{p, m}}{L_{v, r}}$ respectively, for the various liquid-gas systems studied. The differences $\left(A_{2}-A_{1}\right)$ are given in column 9 while the percentage difference $\frac{\left(A_{2}-A_{1}\right)}{A_{2}} 100$ are given in column 10.

Since in this imperfect world one cannot expect perfect agreement between experimental and theoretical values, it is desirable to have some criteria by which the reasonableness of the agreement can be assessed. An error analysis was therefore made to obtain estimates of the accuracy of the calculated "thermodynamic wet-bulb temperature" using the observed, or measured parameters $P, T$, and $r$. It is apparent that an iterative method must be used to solve eq (23) or (24) for $T_{w}$. Furthermore, the parameters $P, T, T_{w}$, and $r$ must be known or assumed in order to obtain values of the enthalpy functions $h(P, T, r), h\left(P, T_{w}, r\right), h\left(P, T_{w}, r_{w}\right)$ and $h_{w}^{\prime}\left(P, T_{w}\right)$, the latent heat of vaporization function $L_{v}^{\prime}\left(T_{w}\right)$ and the saturation mixing ratio function $r_{w}\left(P, T_{w}\right)$. Not only do the measurement errors in $P, T$, and $r$ enter into estimation of the error in $\left(T_{w}\right)_{\text {calc }}$, but experimental and other systematic uncertainties in the enthalpies, latent heats of vaporization and saturation mixing ratios must be accounted for. A similar analysis was made to obtain estimates of the accuracy of the psychrometric factors $A_{1}$ and $A_{2}$ using the observed parameters $P, T, T_{w}$, and $r$. Details of the analyses are given in the appendix, along with the sources of the thermodynamic data and physical constants used in the calculations. The results of the analyses are presented in tables 2,3 , and 4 .
The parameters used in the computation of $\left(T_{w}\right)_{\text {calc }}, A_{1}$ and $A_{2}$ are listed in column 1 of table 2. The nominal magnitudes of the parameters are given in column 2. Estimates of the systematic and random errors in these parameters are given in columns 3 and 4 while the corresponding systematic and random errors in the wet-bulb temperature difference $\left[\left(T_{w}\right)_{\text {obs }}-\left(T_{w}\right)_{\text {calc }}\right]$ and in the psychrometric factor difference $\left(A_{2}-A_{1}\right)$ produced by the estimated errors in these parameters are given in columns $5,6,7$, and 8 . Thus, for example, an estimated systematic error of $0.01 \mathrm{deg} C$ in $T$ for the water-air system produces a corresponding systematic error or $0.005 \mathrm{deg} \mathrm{C}$ in $\left[\left(T_{w}\right)_{\text {obs }}-\left(T_{w}\right)_{\text {calc }}\right]$ in the water-air system. The estimated overall systematic error in $\left[\left(T_{w}\right)_{\text {obs }}-\left(T_{w}\right)_{\text {calc }}\right]$ was obtained by summing the individual systematic errors listed in column 5. Similarly the estimated overall systematic error in $\left(A_{2}-A_{1}\right)$ was obtained by summing the individual systematic errors in column 7 . The estimated overall random error in $\left[\left(T_{w}\right)_{\text {obs }}-\left(T_{w}\right)_{\text {calc }}\right]$ and in $\left(A_{2}-A_{1}\right)$ was obtained by computing the root-mean-square value of the individual random errors in columns 6 and 8, respectively. The estimated overall errors may be considered as guesses of the differences between $\left(T_{w}\right)_{\text {obs }}$ and $\left(T_{w}\right)_{\text {calc }}$ and between $A_{2}$ and $A_{1}$ which may be expected to occur due to systematic and random errors, provided the psychrometer otherwise acted in accordance with eq (1).

Table 3 lists, for each liquid-gas system, the average of $\left[\left(T_{w}\right)_{\text {obs }}-\left(T_{w}\right)_{\text {calc }}\right]$ and an estimate of the standard deviation of the average. Estimates of the overall systematic error and the overall random error, given in table 2 , are repeated here for convenience in making comparisons. Table 4 gives similar values for $\left(A_{2}-A_{1}\right)$. 
TABLE 1. Comparison between wet-bulb temperatures and psychrometric factors

\begin{tabular}{|c|c|c|c|c|c|c|c|c|c|}
\hline \multirow[b]{2}{*}{$\underset{P}{\text { Pressure }}$} & \multirow[b]{2}{*}{ Flow } & \multirow[b]{2}{*}{$\begin{array}{c}\text { Dry-bulb } \\
\text { temperature } \\
T\end{array}$} & \multicolumn{3}{|c|}{ Wet-bulb temperature } & \multicolumn{4}{|c|}{ Psychrometric factor } \\
\hline & & & $\begin{array}{l}\text { Observed } \\
\left(T_{w}\right)_{\text {obs }}\end{array}$ & $\begin{array}{l}\text { Calculated } \\
\left(T_{w}\right)_{\text {calc }}\end{array}$ & {$\left[\begin{array}{c}\text { Difference } \\
{\left[\left(T_{u}\right)_{\text {obs }}-\left(T_{u}\right)_{\text {calc }}\right]}\end{array}\right.$} & $A_{2}=\frac{r_{w}}{\Delta T}$ & $A_{1}=\frac{C_{p, m}}{L_{r, r}}$ & $\begin{array}{c}\text { Difference } \\
\left(\mathrm{A}_{2}-\mathrm{A}_{1}\right)\end{array}$ & $\begin{array}{c}\begin{array}{c}\text { Percentage } \\
\text { difference }\end{array} \\
\frac{\left(A_{2}-A_{1}\right)}{A_{2}} \times 100\end{array}$ \\
\hline Bars & $\begin{array}{l}\text { Liter per } \\
\text { minute }\end{array}$ & $\operatorname{deg} C$ & $\operatorname{deg} C$ & $\operatorname{deg} C$ & $\operatorname{deg} C$ & $10^{-5} / \operatorname{deg} \mathrm{C}$ & $10^{-5} / \operatorname{deg} \mathrm{C}$ & $10^{-5} / \operatorname{deg} \mathrm{C}$ & $\%$ \\
\hline \multicolumn{10}{|c|}{ Water-Air } \\
\hline 0.9745 & 1.4 & 24.80 & 7.87 & 7.86 & 0.01 & 40.65 & 40.57 & 0.08 & 0.2 \\
\hline .9737 & 1.4 & 24.73 & 7.81 & 7.82 & -.01 & $40^{\prime} .54$ & 40.57 & -.03 & -.1 \\
\hline .9816 & 1.4 & 24.62 & 7.80 & 7.83 & -.03 & 40.42 & 40.57 & -.15 & -.4 \\
\hline .9806 & 1.4 & 24.65 & 7.82 & 7.84 & -.02 & 40.49 & 40.57 & -.08 & -.2 \\
\hline 1.0002 & 1.4 & 25.11 & 8.24 & 8.21 & .03 & 40.76 & 40.59 & .17 & .4 \\
\hline 0.9943 & 2.1 & 37.07 & 13.25 & 13.26 & -.01 & 40.71 & 40.75 & -.04 & -.1 \\
\hline .9948 & 2.1 & 37.01 & 13.19 & 13.24 & -.05 & 40.53 & 40.75 & -.22 & -.5 \\
\hline .9943 & 2.1 & 37.02 & 13.27 & 13.24 & .03 & 40.88 & 40.75 & .13 & .3 \\
\hline 0.9978 & 2.1 & 37.02 & 13.23 & 13.27 & -.04 & 40.56 & 40.75 & -.19 & .5 \\
\hline 1.0000 & 2.1 & 24.98 & 8.15 & 8.14 & .01 & 40.61 & 40.58 & .03 & .1 \\
\hline 1.0005 & 2.1 & 25.02 & 8.16 & 8.17 & -.01 & 40.55 & 40.58 & -.03 & -.1 \\
\hline 1.0008 & 2.1 & 25.02 & 8.18 & 8.17 & .01 & 40.64 & 40.59 & .05 & .1 \\
\hline 1.0008 & 2.1 & 25.08 & 8.22 & 8.20 & .02 & 40.70 & 40.59 & .11 & .3 \\
\hline 1.0007 & 2.1 & 25.17 & 8.25 & 8.24 & .01 & 40.65 & 40.59 & .06 & .1 \\
\hline 0.9818 & 6.2 & 24.88 & 8.07 & 7.95 & .12 & 41.19 & 40.58 & .61 & 1.5 \\
\hline .9829 & 6.2 & 24.85 & 8.10 & 7.95 & .15 & 41.38 & 40.58 & .80 & 1.9 \\
\hline
\end{tabular}

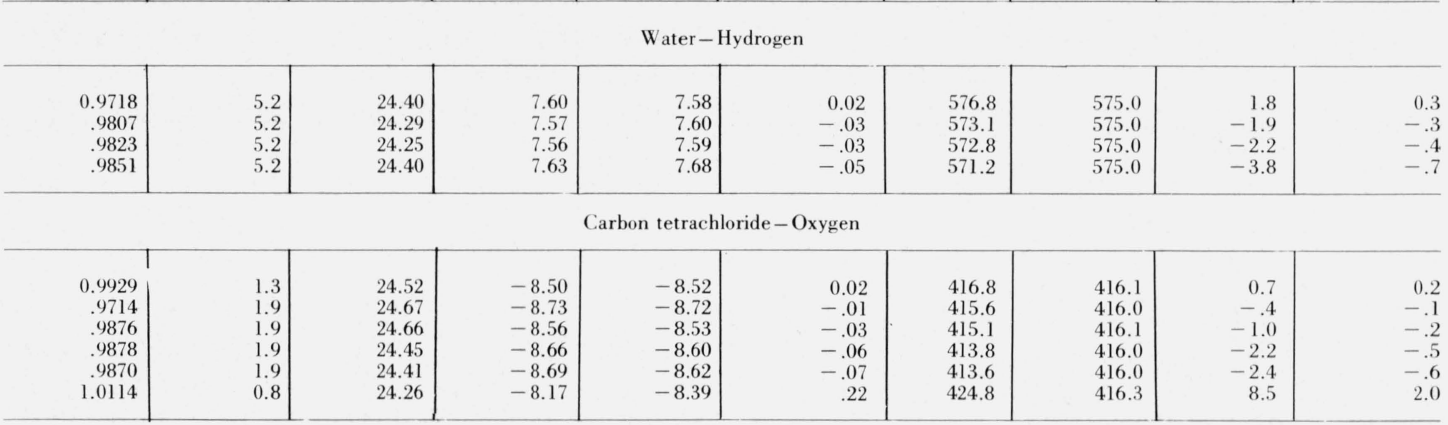

\begin{tabular}{|c|c|c|c|c|c|c|c|c|c|}
\hline \multicolumn{10}{|c|}{ Carbon tetrachloride-Hydrogen } \\
\hline $\begin{array}{r}1.0061 \\
0.9970 \\
.9839 \\
.9843 \\
.9848\end{array}$ & $\begin{array}{l}2.1 \\
2.1 \\
2.9 \\
2.9 \\
2.9\end{array}$ & $\begin{array}{l}23.93 \\
23.82 \\
24.18 \\
24.20 \\
24.12\end{array}$ & $\begin{array}{l}-8.71 \\
-8.83 \\
-8.96 \\
-8.98 \\
-9.01\end{array}$ & $\begin{array}{l}-8.83 \\
-8.97 \\
-9.00 \\
-8.99 \\
-9.01\end{array}$ & $\begin{array}{r}0.12 \\
.14 \\
.04 \\
.01 \\
.00\end{array}$ & $\begin{array}{l}6.519 \\
6.531 \\
6.471 \\
6.453 \\
6.447\end{array}$ & $\begin{array}{l}6.451 \\
6.450 \\
6.449 \\
6.449 \\
6.448\end{array}$ & $\begin{array}{r}68 \\
81 \\
22 \\
4 \\
-1\end{array}$ & $\begin{array}{r}1.0 \\
1.2 \\
.3 \\
.1 \\
-.0\end{array}$ \\
\hline \multicolumn{10}{|c|}{ Toluene-Air } \\
\hline $\begin{array}{r}0.9981 \\
.9986 \\
.9923 \\
.9930 \\
.9764 \\
.9784 \\
1.0056 \\
1.0075\end{array}$ & $\begin{array}{l}1.4 \\
1.4 \\
1.4 \\
1.4 \\
2.1 \\
2.1 \\
0.8 \\
0.8\end{array}$ & $\begin{array}{l}25.47 \\
25.37 \\
25.15 \\
25.13 \\
25.58 \\
25.54 \\
25.09 \\
24.98\end{array}$ & $\begin{array}{l}6.79 \\
6.74 \\
6.65 \\
6.65 \\
6.65 \\
6.62 \\
6.90 \\
6.90\end{array}$ & $\begin{array}{l}6.84 \\
6.80 \\
6.64 \\
6.64 \\
6.70 \\
6.70 \\
6.73 \\
6.70\end{array}$ & $\begin{array}{r}-0.05 \\
-.06 \\
.01 \\
.01 \\
-.05 \\
-.08 \\
.08 \\
.17 \\
.20\end{array}$ & $\begin{array}{l}236.8 \\
236.5 \\
238.4 \\
238.5 \\
236.8 \\
236.0 \\
242.9 \\
243.9\end{array}$ & $\begin{array}{l}238.2 \\
238.2 \\
238.2 \\
238.2 \\
238.2 \\
238.2 \\
238.3 \\
238.3\end{array}$ & $\begin{array}{r}-1.4 \\
-1.7 \\
0.2 \\
0.3 \\
-1.4 \\
-2.2 \\
4.6 \\
5.6\end{array}$ & $\begin{array}{r}-0.6 \\
-.7 \\
.1 \\
.1 \\
-.6 \\
-.9 \\
1.9 \\
2.3\end{array}$ \\
\hline
\end{tabular}

If the errors in $\left(T_{w}\right)_{\text {obs }}$ and $\left(T_{w}\right)_{\text {cale }}$, or in $A_{2}$ and $A_{1}$, were solely random, then the average of the appropriate difference, for a given liquid-gas system, would tend toward zero. Since the averages are not equal to zero, one would expect that these values are experimental measures of the systematic errors and should therefore have the same magnitudes as the estimates of the overall systematic errors. The standard deviations of the differences about these averages, on the other hand, are indicators of the experimental random errors and so, correspondingly, should have a close relationship to the estimates of the overall random errors.
It can be observed from table 3 that the average values of $\left[\left(T_{w}\right)_{\text {obs }}-\left(T_{u}\right)_{\text {calc }}\right]$ are smaller than the estimates of the overall systematic errors of $\left[\left(T_{w}\right)_{\mathrm{obs}}\right.$ $-\left(T_{u}\right)_{\text {calc }}$. This is also the case for $\left(A_{2}-A_{1}\right)$ as shown in table 4 . This is probably due to an overly conservative estimate of the individual systematic errors of the parameters (especially $f_{w}$ ) and the fact that summing the corresponding individual systematic errors of the appropriate differences gives a maximum.

It can be observed further from tables 3 and 4 that the estimates of the standard deviations are considerably greater than the estimates of the over- 
TABLE 2. Error analysis

\begin{tabular}{|c|c|c|c|c|c|c|c|}
\hline \multirow{3}{*}{ Parameter } & \multirow{3}{*}{$\begin{array}{c}\text { Nominal } \\
\text { magnitude } \\
\text { of } \\
\text { parameter }\end{array}$} & \multicolumn{2}{|c|}{$\begin{array}{l}\text { Estimated error of } \\
\text { the parameter }\end{array}$} & \multicolumn{2}{|c|}{$\begin{array}{c}\text { Estimated error of } \\
{\left[\left(T_{w}\right)_{\text {obs }}-\left(T_{w}\right)_{\text {calc }}\right]} \\
\text { due to parameter error }\end{array}$} & \multicolumn{2}{|c|}{$\begin{array}{c}\text { Estimated error of } \\
\left(A_{2}-A_{1}\right) \\
\text { due to parameter error }\end{array}$} \\
\hline & & \multirow{2}{*}{ Systematic } & \multirow{2}{*}{ Random* } & Systematic & Random & Systematic & Random \\
\hline & & & & $\operatorname{deg} C$ & $\operatorname{deg} \mathrm{C}$ & $10^{-5} / \operatorname{deg} \mathrm{C}$ & $10^{-5} / \mathrm{deg} \mathrm{C}$ \\
\hline \multicolumn{8}{|c|}{ Water-Air } \\
\hline 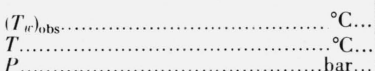 & $\begin{array}{c}8 . \\
25 .\end{array}$ & $\begin{array}{r}0.01 \\
.01\end{array}$ & $\begin{array}{c}0.015 \\
.024 \\
0002\end{array}$ & $\begin{array}{r}0.010 \\
.005\end{array}$ & $\begin{array}{r}0.015 \\
.011\end{array}$ & $\begin{array}{r}0.052 \\
.024\end{array}$ & $\begin{array}{r}0.08 \\
.06\end{array}$ \\
\hline 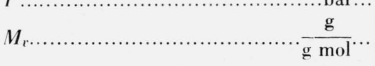 & 18.01534 & .00006 & & .000 & & .000 & \\
\hline 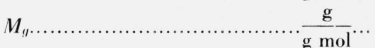 & 28.9645 & .0009 & & .000 & & .000 & \\
\hline 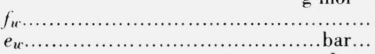 & $\begin{array}{l}1.004 \\
0.0107\end{array}$ & \begin{tabular}{l|}
.0008 \\
.0000043
\end{tabular} & & $\begin{array}{l}.006 \\
.003\end{array}$ & & $\begin{array}{l}.033 \\
.016\end{array}$ & \\
\hline 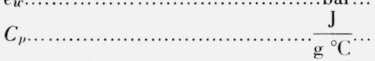 & 1.0 & .00036 & & .003 & & .015 & \\
\hline$\ldots \ldots \ldots \ldots \ldots \ldots \ldots \ldots \ldots \ldots \ldots \ldots$ & 33. & .025 & & .000 & & .000 & \\
\hline$\ldots \ldots \ldots \ldots \ldots \ldots \ldots \ldots \ldots \ldots$ & 2,516 & .084 & & .000 & & .001 & \\
\hline Estimated overall error...................... & & & & .027 & .019 & .14 & .10 \\
\hline \multicolumn{8}{|c|}{ Water-Hydrogen } \\
\hline 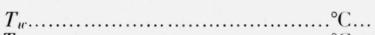 & 8. & 0.01 & 0.015 & 0.010 & 0.015 & 0.74 & 1.11 \\
\hline$T$ T & 25. & .01 & .024 & .005 & .011 & .35 & 0.83 \\
\hline 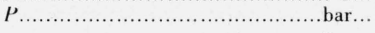 & 1.0 & .01 & .0002 & & .002 & & .12 \\
\hline$M_{r} \ldots \ldots \ldots \ldots \ldots \ldots \ldots \ldots \ldots \ldots \ldots \ldots \ldots \ldots \ldots \ldots \ldots \ldots \ldots$ & 18.01534 & .00006 & & .000 & & .00 & \\
\hline$M_{g} \ldots \ldots \ldots \ldots \ldots \ldots \ldots \ldots \ldots \ldots \ldots \ldots \ldots \ldots$ & 2.01594 & .00001 & & .000 & & .010 & \\
\hline 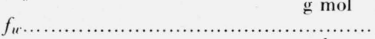 & 1. & .005 & & .039 & & 2.91 & \\
\hline 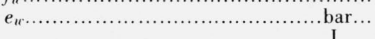 & 0.0104 & .0000042 & & .003 & & $\begin{array}{r}2.91 \\
.23\end{array}$ & \\
\hline 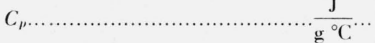 & 14.2 & .00042 & & .000 & & .02 & \\
\hline 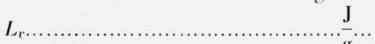 & 2,483 & 1.76 & & .005 & & .40 & \\
\hline Estimated overall error......................... & & & & .062 & .020 & 4.65 & 1.39 \\
\hline \multicolumn{8}{|c|}{ Carbon Tetrachloride-Oxygen } \\
\hline 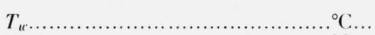 & & 0.01 & 0.015 & 0.010 & 0.015 & 0.37 & 0.56 \\
\hline 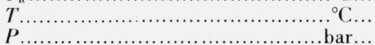 & 25. & .01 & $\begin{array}{l}.024 \\
.0002\end{array}$ & .003 & $\begin{array}{r}.008 \\
002\end{array}$ & .12 & .31 \\
\hline $\mathrm{M}_{\mathrm{g}}$ & 5382315 & 002 & & & & & \\
\hline 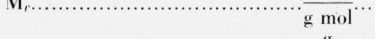 & 53.82315 & .002 & & .000 & & .00 & \\
\hline 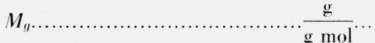 & 31.9988 & .0001 & & .000 & & .00 & \\
\hline 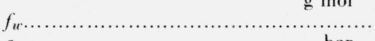 & 1. & .005 & & .057 & & 2.14 & \\
\hline 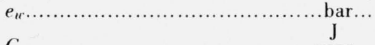 & 0.027 & .000093 & & .038 & & 1.46 & \\
\hline 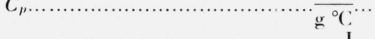 & .92 & .000167 & & .002 & & 0.9 & \\
\hline 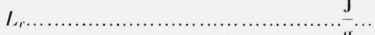 & 214. & 1.09 & & .055 & & 2.14 & \\
\hline Estimated overall error... & & & & .165 & .017 & 6.32 & .65 \\
\hline \multicolumn{8}{|c|}{ Carbon Tetrachloride-Hydrogen } \\
\hline 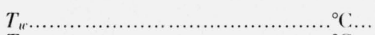 & -9 & 0.01 & 0.015 & 0.010 & 0.015 & 6.0 & 8.9 \\
\hline$T$ & 25. & .01 & .024 & .003 & .008 & 2.0 & 4.7 \\
\hline 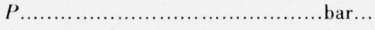 & 1.0 & & .0002 & & .002 & .1 & 1.3 \\
\hline$M_{r} \ldots \ldots \ldots \ldots \ldots \ldots \ldots \ldots \ldots \ldots \ldots \ldots \ldots \ldots \ldots \ldots \ldots$ & 153.82315 & .002 & & .000 & & .1 & \\
\hline$M \quad \stackrel{g}{g}$ & 201594 & & & & & & \\
\hline 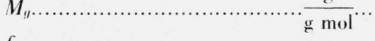 & 2.01594 & .00001 & & .000 & & .0 & \\
\hline 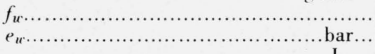 & $\begin{array}{l}1 . \\
0.027\end{array}$ & $\begin{array}{l}.005 \\
.000091\end{array}$ & & $\begin{array}{l}.056 \\
.038\end{array}$ & & $\begin{array}{l}33.2 \\
22.6\end{array}$ & \\
\hline 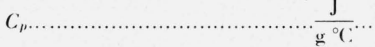 & 13.4 & .00406 & & .000 & & 0.2 & \\
\hline 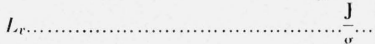 & 214. & 1.09 & & .054 & & 32.9 & \\
\hline Estimated overall error............ & & & & .161 & .017 & 97.0 & 10.1 \\
\hline \multicolumn{8}{|c|}{ Toulene-Air } \\
\hline $\begin{array}{l}T_{1} \ldots \ldots \ldots \ldots \ldots \ldots \ldots \ldots \ldots \ldots \ldots \ldots \ldots \\
{ }_{T}{ }^{\circ} \mathrm{C} \ldots \\
\end{array}$ & $\begin{aligned} 7 . & \\
25 . & \end{aligned}$ & $\begin{array}{r}0.01 \\
.01\end{array}$ & $\begin{array}{r}0.015 \\
.024\end{array}$ & $\begin{array}{r}0.010 \\
.004\end{array}$ & $\begin{array}{r}0.015 \\
.010\end{array}$ & $\begin{array}{r}0.27 \\
.13\end{array}$ & $\begin{array}{r}0.40 \\
.31\end{array}$ \\
\hline
\end{tabular}


TABLE 2. Error analysis-Continued

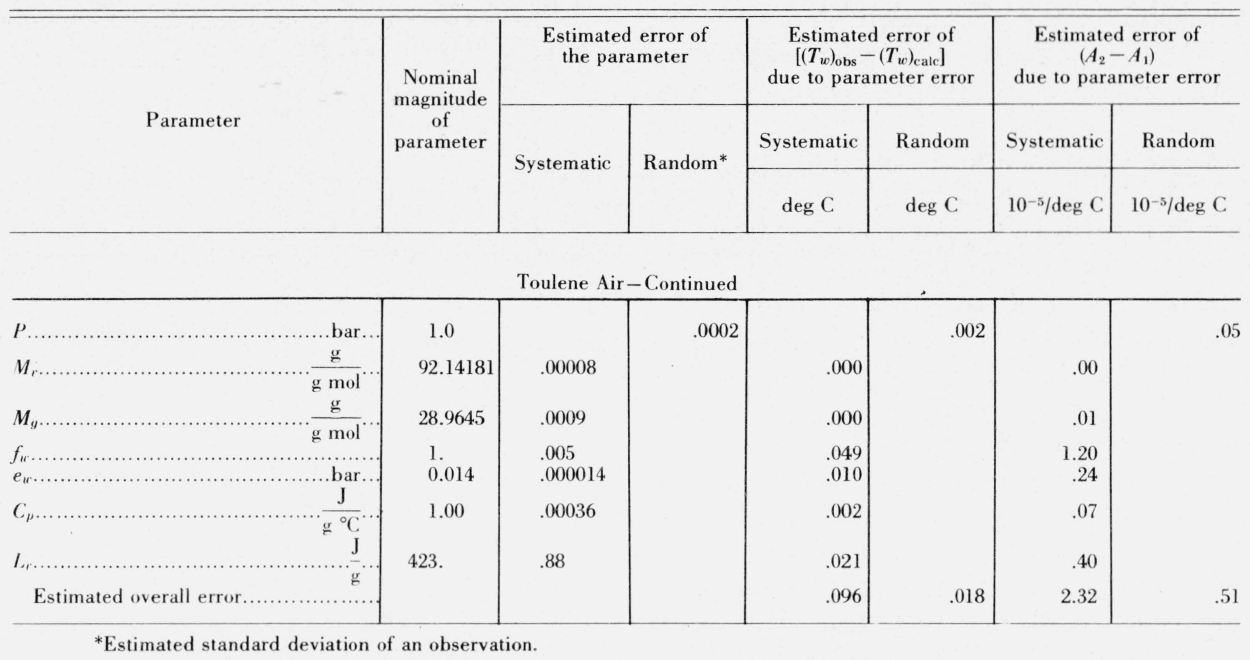

TABLE 3. Summary of wet-bulb temperature differences $\left[\left(\mathrm{T}_{\mathrm{w}}\right)_{o b s}-\left(\mathrm{T}_{\mathrm{w}}\right)_{c a l c}\right]$

\begin{tabular}{|c|c|c|c|c|c|c|}
\hline System & Average & $\begin{array}{l}\text { Standard } \\
\text { deviation } \\
\text { of the dif- } \\
\text { ferences } \\
\text { about the } \\
\text { average }\end{array}$ & $\begin{array}{c}\text { Estimated } \\
\text { overall } \\
\text { system- } \\
\text { atic error } \\
\Delta_{*}\end{array}$ & $\begin{array}{c}\text { Estimated } \\
\text { overall } \\
\text { random } \\
\text { error* } \\
\Delta_{r}\end{array}$ & $\begin{array}{c}\begin{array}{c}\text { Estimated } \\
\text { total } \\
\text { error }\end{array} \\
\left(\Delta_{r}+\Delta_{r}\right)\end{array}$ & $\begin{array}{c}\begin{array}{c}\text { Rejection } \\
\text { criterion }\end{array} \\
\left(\Delta_{s}+3 \Delta_{r}\right)\end{array}$ \\
\hline & $\operatorname{deg} C$ & $\operatorname{deg} C$ & $\operatorname{deg} C$ & $\operatorname{deg} C$ & $\operatorname{deg} C$ & $\operatorname{deg} C$ \\
\hline $\mathrm{H}_{2} \mathrm{O}-\mathrm{Air}$ & +0.015 & 0.053 & 0.027 & 0.019 & 0.046 & 0.084 \\
\hline $\begin{array}{l}\mathrm{H}_{2} \mathrm{O} \text {-Air } \\
\text { (Restricted flow) }\end{array}$ & -.003 & .026 & .027 & .019 & .046 & \\
\hline $\mathrm{H}_{2} \mathrm{O} \cdot \mathrm{H}_{2}$ & -.021 & .033 & .062 & .020 & .082 & .122 \\
\hline $\mathrm{CCl}_{4} \mathrm{O}_{2}$ & +.013 & .108 & .165 & .017 & .182 & .216 \\
\hline $\begin{array}{l}\mathrm{CCL}_{1} \mathrm{O}_{2} \\
\quad \text { (Restricted flow) }\end{array}$ & -.029 & .035 & .165 & .017 & .182 & \\
\hline $\mathrm{CCl}_{1} \cdot \mathrm{H}_{2}$ & +.060 & .064 & .161 & .017 & .178 & .212 \\
\hline ( $-\mathrm{H}_{\mathrm{x}}$ - Air & +.018 & .109 & .096 & .018 & .114 & .150 \\
\hline $\begin{array}{l}\text { ( }-\mathrm{H}_{\mathrm{x}} \text {-Air } \\
\text { (Restricted flow) }\end{array}$ & -.038 & .042 & .096 & .018 & .114 & \\
\hline
\end{tabular}

*Estimated standard deviation of an observation.

TABLE 4. Summary of psychrometric factor differences $\left(A_{2}-A_{1}\right)$

\begin{tabular}{|c|c|c|c|c|c|c|}
\hline System & Average & $\begin{array}{l}\text { Standard } \\
\text { deviation } \\
\text { of the dif- } \\
\text { ferences } \\
\text { about the } \\
\text { average }\end{array}$ & $\begin{array}{l}\text { Relative } \\
\text { average }\end{array}$ & $\begin{array}{c}\text { Estimated } \\
\text { overall } \\
\text { system- } \\
\text { atic error } \\
\Delta_{*}\end{array}$ & $\begin{array}{c}\text { Estimated } \\
\text { overall } \\
\text { random } \\
\text { error* } \\
\Delta_{r}\end{array}$ & $\begin{array}{c}\text { Estimated } \\
\text { total } \\
\text { error } \\
\\
\left(\Delta_{s}+\Delta_{r}\right)\end{array}$ \\
\hline $\begin{array}{l}\mathrm{H}_{2} \mathrm{O}-\mathrm{Air} \\
\mathrm{H}_{2} \mathrm{O} \text {-Air } \\
\quad \text { (Restricted flow) }\end{array}$ & $\begin{array}{c}10^{-5} / \operatorname{deg} C \\
+0.08 \\
-.01\end{array}$ & $\begin{array}{c}10^{-5} / \operatorname{deg} C \\
0.27 \\
.12\end{array}$ & $\begin{array}{c}\% \\
.19 \\
-.02\end{array}$ & $\begin{array}{c}10^{-5} / \operatorname{deg} C \\
0.14 \\
.14\end{array}$ & $\mid \begin{array}{c}10^{-5} / \operatorname{deg} C \\
0.10 \\
.10\end{array}$ & $\begin{array}{c}10^{-5} / \operatorname{deg} C \\
0.24 \\
.24\end{array}$ \\
\hline $\begin{array}{l}\mathrm{H}_{2} \mathrm{O} \cdot \mathrm{H}_{2} \\
\left(\mathrm{CL}_{1} \cdot \mathrm{O}_{2}\right. \\
\left(\mathrm{CC}_{1} \cdot \mathrm{O}_{2}\right. \\
\quad \text { (Restricted flow) }\end{array}$ & $\begin{array}{l}-1.6 \\
+0.5 \\
-1.1\end{array}$ & $\begin{array}{l}2.4 \\
4.0 \\
1.4\end{array}$ & $\begin{array}{l}-.27 \\
+.12 \\
-.26\end{array}$ & $\begin{array}{l}4.65 \\
6.32 \\
6.32\end{array}$ & $\begin{array}{r}1.39 \\
0.65 \\
.65\end{array}$ & $\begin{array}{l}6.04 \\
6.97 \\
6.97\end{array}$ \\
\hline $\begin{array}{l}\left(\mathrm{Cl}_{4} \cdot \mathrm{H}_{2}\right. \\
\left(-\mathrm{H}_{\mathrm{H}} \text {-Air }\right. \\
\left(\mathrm{C}_{\mathrm{*}} \text {-Air }\right. \\
\text { (Restricted flow) }\end{array}$ & $\begin{array}{l}+35 . \\
+0.5 \\
-1.0\end{array}$ & $\begin{array}{l}37 . \\
3.0 \\
1.0\end{array}$ & $\begin{array}{l}+.25 \\
+.21 \\
-.43\end{array}$ & $\begin{array}{r}97 . \\
2.3 \\
2.3\end{array}$ & $\begin{array}{r}10 . \\
0.5 \\
.5\end{array}$ & $\begin{array}{r}107 . \\
2.8 \\
2.8\end{array}$ \\
\hline
\end{tabular}

*Estimated standard deviation of an observation.

all random errors. The overall random errors were based on estimates of the individual random error to be expected in measurement of each of the parameters in a system in static equilibrium. The measurements were made in a dynamic system under conditions close to steady-state, but with some fluctuation of inlet temperature. Since the thermocouple emfs were not read simultaneously and since the wet-bulb thermocouple does not respond to changes in inlet temperature as rapidly as does the dry-bulb thermocouple, it is likely that the actual random temperature errors were greater than that estimated. That the standard deviation was approximately twoto three-fold the estimated overall (static) random error, does not seem disturbing, but does indicate that some contributory effects were not accounted for.

Examining the data in table 1 , one finds that there are several sets of measurements which yielded excessively large individual differences in $\left[\left(T_{w}\right)_{\mathrm{obs}}\right.$ $-\left(T_{w}\right)_{\text {calc }} \mid$.

The criterion was established to reject any difference which exceeded the sum of the estimated overall systematic error plus three times the estimated overall random error in $\left[\left(T_{w}\right)_{\text {obs }}-\left(T_{w}\right)_{\text {calc }} \mid\right.$. It was assumed that such large differences represented anomalous behavior of the psychrometer. The application of this criterion led to the rejection of two sets of data for the water-air system, one set of data for the carbon tetrachloride-oxygen system, and two sets of data for the toluene-air system. These rejected sets of data included all experiments performed at the lowest and highest flow rates, that is, at 0.8 and 6.2 liters per minute, and none within the flow rate range of 1.3 through 5.2 liters per minute.

Average differences and estimates of the standard deviations of the average differences were recomputed excluding the rejected differences, and are given in tables 3 and 4 under the heading "restricted flow." Whereas the average algebraic differences initially were positive in sign for the water-air, carbon tetrachloride-oxygen, and toluene-air systems, after applying the rejection criterion, the sign in each case was negative. The magnitude of the average algebraic difference decreased by a factor of five for the water-air system, but doubled for the carbon tetrachloride-oxygen and toluene-air systems. The new ("restricted flow") estimates of the standard deviations were smaller by a factor of about two to three 
and agreed more closely with the estimates of the overall random error.

It appears that the rejection process eliminated both low and high flow-dependent systematic errors. This is to be expected since at very low flows heat losses to the ambient atmosphere become a noticeable fraction of the heat supplied by the test gas. At very high flows, incomplete saturation and incomplete heat exchange apparently occur.

Corrections or error estimates could be made for radiative or conductive heat losses, incomplete saturation, change of kinetic energy of the gas stream, heat supplied by incoming liquid or other factors that might tend to affect the performance of the psychrometer. In designing this instrument, an attempt was made to make these sources of error as negligible as feasible, so that corrections would not need to be applied. Since the purpose of these tests was to determine how well the instrument actually performed its intended function as an adiabatic saturation psychrometer, such corrections were not made in this evaluation.

Though on the average the measured wet-bulb temperatures differ little from the calculated wetbulb temperatures, there is a prevalence for the measured temperature to be lower than the calculated temperature for the "restricted flow" cases. This probably stems from the fact that the true $f_{w}$-factor is greater than unity whereas a value of one was used for all systems except water-air in determining $\left(T_{w}\right)_{\text {calc }}$.

For the water-air system, for which the $f_{w}$-factor is known and therefore was used, $\left(T_{w}\right)_{\text {calc }}$ is much closer to $\left(T_{w}\right)_{\text {obs }}$ on the average than for any other system.

The response time traces obtained appeared to have the general shape of exponential functions as one would expect. The time constant $\tau$ was obtained by measuring the time required for the wetbulb temperature to undergo 63 percent of its total change for each test condition. Figure 4 is a plot of these measured time constants against gas flow rate for the two conditions tested. The time constant is a function of gas flow rate. At flow rates of 3.75 to 5.2 liters per minute the time constant is about $3 / 4$ of a minute.

Although the temperature of the liquid at the point where it discharges onto the wicking was not measured, several calculations were made to obtain estimates of how close this temperature approached the "thermodynamic wet-bulb temperature." For example, with water flowing at a rate calculated to be three-fold that required to saturate an air flow of $1^{1 / 2}$ liters per minute at inlet conditions of zero mixing ratio, $25{ }^{\circ} \mathrm{C}$ dry-bulb temperature, and 1 bar pressure, the liquid feed temperature was calculated to be $0.2{ }^{\circ} \mathrm{C}$ higher than "thermodynamic wet-bulb temperature." This, it was estimated, would elevate the wetbulb temperature by approximately $0.008{ }^{\circ} \mathrm{C}$. If the inlet relative humidity of the gas were higher, the other inlet and flow conditions remaining unchanged, the absolute temperature error in the liquid feed would be less, but the percentage error in the experimental psychrometric factor, would be the same.

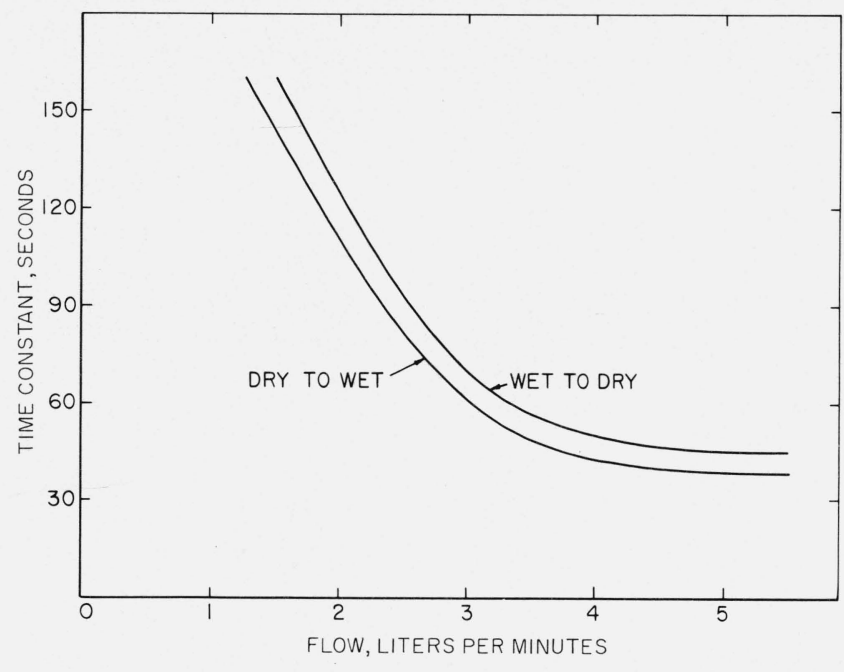

FIGURE 4. Time constant versus inlet gas flow rate for water-air system.

It is important to reiterate that the adiabatic saturation psychrometer behaves very differently from conventional types of psychrometers. This is shown in table 5 which compares the psychrometric factor ratios $A_{2} / A_{1}$ at $r=0$ obtained at NBS with the adiabatic saturation psychrometer and with three types of conventional thermocouple psychrometers corrected for radiation losses; it also lists ratios based on results reported by other investigators on conventional psychrometers. The ratio is essentially unity for the adiabatic saturation psychrometer for the five systems listed; it differs significantly from unity for the conventional types of psychrometer, although for the water-air system the magnitude of the difference is smaller than for the other systems.

TABLE 5. Typical psychrometer performance

\begin{tabular}{|c|c|c|c|c|c|c|c|c|}
\hline \multirow{3}{*}{ System } & \multirow{3}{*}{$\begin{array}{l}\text { Ratio of } \\
\text { thermal } \\
\text { to mass } \\
\text { diffusiv- } \\
\text { ities }\end{array}$} & \multicolumn{7}{|c|}{ Ratio of psychrometric factors, $A_{2} / A_{1}$} \\
\hline & & \multicolumn{4}{|c|}{ NBS instruments } & \multicolumn{3}{|c|}{ Other instruments } \\
\hline & & $\begin{array}{l}\text { Adiabatic } \\
\text { satura- } \\
\text { tion psy- } \\
\text { chrom- } \\
\text { eter }^{\mathrm{a}}\end{array}$ & $\begin{array}{l}\text { Thermo- } \\
\text { couple } \\
\text { psy- } \\
\text { chrom- } \\
\text { eter } A^{b}\end{array}$ & $\begin{array}{l}\text { Thermo- } \\
\text { couple } \\
\text { psy- } \\
\text { chrom- } \\
\text { eter } \mathrm{B}^{\mathrm{b}}\end{array}$ & $\begin{array}{l}\text { Thermo- } \\
\text { couple } \\
\text { psy- } \\
\text { chrom- } \\
\text { eter C" }\end{array}$ & $\begin{array}{l}\text { Arnold } \\
{[11]^{\mathrm{b}}}\end{array}$ & $\begin{array}{l}\text { Sher- } \\
\text { wood } \\
{[12]}\end{array}$ & $\begin{array}{c}\text { Lewis } \\
\text { [13] }\end{array}$ \\
\hline $\mathrm{H}_{2} \mathrm{O}$-Air & 0.9 & 1.000 & 1.14 & 1.04 & & 0.95 & 1.21 & \\
\hline $\mathrm{H}_{2} \mathrm{O} \cdot \mathrm{H}_{2}$ & 1.7 & 0.997 & 1.64 & 1.47 & 1.53 & & & \\
\hline $\mathrm{CCl}_{4} \cdot \mathrm{O}_{2}$ & 3.0 & .997 & 2.33 & & 2.23 & & & \\
\hline $\mathrm{CCl}_{4} \cdot \mathrm{H}_{2}$ & 4.5 & 1.005 & & & 2.79 & & & \\
\hline $\mathrm{C}_{7} \mathrm{H}_{\mathrm{v}}$ - Air & 2.6 & 0.996 & & 2.07 & 1.96 & 1.77 & 2.08 & 2.5 \\
\hline
\end{tabular}

Shielded against radiation.

" Corrected for radiation.

\section{Discussion and Conclusions}

The theoretical basis governing the operation of this instrument has been demonstrated at room temperature, atmospheric pressure, and over the flow range of 1.3 through 5.3 liters per minute, by tests with several liquid-gas systems subject to the re- 
striction that the data were limited to the condition $r=0$. Since zero mixing ratio produces the maximum wet-bulb depression for any given dry-bulb temperature, and since such effects as radiative and conductive heat losses tend to have a greater influence with increasing depression, the $r=0$ condition subjects the psychrometer to its severest experimental test. Use of the gas temperature just beyond the outlet end of the saturator tube rather than the temperature of the moistened wicking as the wet-bulb temperature further increases the assurance that this instrument is producing "thermodynamic wet-bulb temperatures." Since essentially all cooling of the incoming gas occurs by heat transfer from the gas to the moistened wicking, the average temperature of the moistened wicking must of necessity be equal to or less than the average temperature of the exit gas. It is possible under some circumstances (for example, where the ratio of thermal to mass diffusivity is less than 1) for the moistened wicking to be cooled below the "thermodynamic wet-bulb temperature," but it is extremely unlikely that the average temperature of the exit gas could be as low as the "thermodynamic wet-bulb temperature" without satisfying the postulates that form the theoretical basis for eq (1).

Although the intended use of this instrument is to measure the water vapor content of gases, it is possible to use it for the determination of other vapors in gases and perhaps for the determination of $f_{w}$ for particular vapor-gas combinations. The latter might be done by controlling inlet gas temperatures in such a way as to produce wet-bulb temperatures which correspond to those at which the vapor pressure and latent heat of evaporation of the liquid are well known.

Due to the difficulty of producing known vapor concentrations in gases other than zero, this instrument was only tested at the condition $r=0$. Its performance characteristics, therefore, have been demonstrated only at this condition. We believe however, that the characteristics would not be altered significantly were the psychrometer operated at $r>0$. Furthermore, as mentioned above, for any given dry-bulb temperature, $r=0$ produces the minimum wet-bulb temperature and subjects the psychrometer to the maximum radiative and conductive heat losses, and hence is the most severe condition under which to test the behavior of a psychrometer.

It is of interest to predict how well one could measure the water vapor content of air with this psychrometer. Whereas the magnitude of the error in wet-bulb temperature probably is related directly to the difference between wet- and dry-bulb temperatures, we will use for our prediction the error obtained at $r=0$ which is in all likelihood maximum since the wet- and dry-bulb temperature difference is maximum, and handle it as though it were a fixed error although it is likely smaller at higher relative humidities. For our estimate of this error we will use the average value of $\left[\left(T_{w}\right)_{\text {obs }}-\left(T_{w}\right)_{\text {calc }}\right]$ plus one standard deviation of this quantity obtained from the "restricted flow" test points. This should give us a one-sigma error estimate. Assuming a dry-bulb temperature of $25^{\circ} \mathrm{C}$, a total pressure of 1 bar, and using the above error in wet-bulb temperature, it is estimated that the psychrometer can be used to determine the relative humidity to within $1 / 4$ percent. Table 6 gives the error estimates in both the mixing ratio and relative humidity determination at various inlet relative humidities.

TABLE 6. Estimated instrument error for water vapor-air system at $25{ }^{\circ} \mathrm{C}, 1$ bar pressure and various relative humidities

\begin{tabular}{r|c|c}
\hline \hline $\mathrm{RH}$ & $\Delta r$ & $\Delta \mathrm{RH}$ \\
\hline$\%$ & $g$ vapor/g vapor-free gas & $\%$ \\
\hline 0 & 0.000025 & \\
20 & .000029 & .13 \\
40 & .000034 & .17 \\
60 & .000038 & .19 \\
80 & .000043 & .21 \\
100 & .000049 & .23 \\
\hline
\end{tabular}

The suggestions and criticisms of L. P. Harrison, ESSA, Weather Bureau, Silver Spring, Md., are gratefully acknowledged.

\section{Appendix. Computations and Sources of Constants}

$\left(T_{w}\right)_{\text {calc }}$ was computed for each experimental point by solving one of the following equations in an iterative manner, using measured values of $P$ and $T$ :

$$
\begin{aligned}
& h(P, T, 0)=h\left(P, T_{w}, r_{w}\right)-r_{w} h_{w}^{\prime}\left(P, T_{w}\right) \\
& h(P, T, 0)=h\left(P, T_{w}, 0\right)+r_{w} L_{v}^{\prime} .
\end{aligned}
$$

$A_{2}$ was computed for each experimental point equating $A_{2}$ to $A$ in eq (13) into which the measured values of $P, T$, and $T_{w}$ were substituted. $A_{1}$ was computed for each experimental point by using one of the following equations into which the measured values of $P, T$, and $T_{w}$ were substituted;

$$
A_{1}=\frac{r_{w}\left[h(P, T, 0)-h\left(P, T_{w}, 0\right)\right]}{\Delta T\left[h\left(P, T_{w}, r_{w}\right)-h\left(P, T_{w}, 0\right)-r_{w} h_{w}^{\prime}\left(P, T_{w}\right)\right]}
$$

$A_{1}=\frac{\left[h(P, T, 0)-h\left(P, T_{w}, 0\right)\right]}{\Delta T L_{v}^{\prime}}$

where $A_{1}$ is the equivalent of $A$ in eq (9).

Equations (22) and (24) were used for the water-air system and are exact. Equations (23) and (25) are approximations and were used for all other systems because neither the gas mixture enthalpy $h\left(P, T_{w}, r_{w}\right)$ nor the "effective" latent heat of vaporization $L_{v}, r$ for these systems was known.

In all cases $r_{w}$ was determined by solution of the following equation: 


$$
r_{w}=\frac{M_{v}}{M_{g}} \frac{f_{w} e_{w}}{\left(P-f_{w} e_{w}\right)}
$$

where $f_{w}=$ a function of pressure and temperature for a given liquid-gas system. ${ }^{3}$

Each of the individual errors in $\left(T_{w}\right)_{\text {calc }}$ is associated with an error in one of the parameters entering into its calculation. The error in $\left(T_{w}\right)_{\text {calc }}$ was obtained by solving eq (22) or (23), as appropriate, using the parameter value plus its estimated error in the calculation and subtracting $\left(T_{w}\right)_{\text {calc }}$ from the result. The individual errors in $\left(A_{2}-A_{1}\right)$ were obtained by solving equations (13) and (24) or (25) as appropriate, using the parameter value plus its estimated error in the calculation along with the values of $\left(T_{w}\right)_{\text {calc }}$ obtained from prior computation. The solution of these equations gives the error directly since $A_{2}-A_{1}=0$ at $\left(T_{w}\right)_{\text {calc }}$ when there are no errors.

The results of the error computations are given in table 2.

Water-Air System. $h(P, T, r), h\left(P, T_{w}, r\right)$ and $h(P$, $\left.T_{w}, r_{w}\right)$ were obtained by solution of the following equation:

$h=\frac{7}{2} R\left[T+\frac{8}{7} r \frac{M_{g}}{M_{v}}(T+1354.74)\right]+\Delta h$

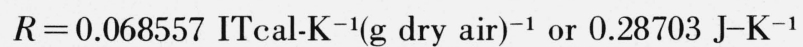

(g dry air $)^{-1}$.

and $\Delta h$ was obtained from table 85 of the Smithsonian Meterological Tables [31].

Values of $h_{w}^{\prime}$ were linearly interpolated from a table given by Goff [24] and values of $f_{w}$ were obtained by linear interpolation in both $T$ and $P$ from values given in Table 89 of the Smithsonian Meteorological Tables [31]. The saturation vapor pressure of water was obtained by solution of an equation given by Goff [32]. The estimated errors in these parameters are given in table 2.

Water-Hydrogen System. $h(P, T, 0)$ and $h(P, T w, 0)$ were obtained for vapor-free hydrogen by linear temperature interpolation of the tabulated values given by Hilsenrath [33]. Values of $L_{v}^{\prime}$ were obtained from steam tables [34]. In the absence of data on the factor $f_{w}$ at the experimental test conditions, a value of unity was assumed for $f_{w}$. Values of $e_{w}$ were obtained in the same manner as with the water-air system. The estimated errors in these parameters are given in table 2.

Carbon Tetrachloride-Oxygen System. $h(P, T, 0)$ and $h\left(P, T_{w} 0\right)$ were obtained for vapor-free oxygen by linear temperature interpolation of tabulated values given by Hilsenrath [33]. Values of $L_{v}^{\prime}$ were obtained by linear interpolation from the tabulation in the International Critical Table [35]. A value of unity was ascribed to $f_{w}$ and vapor pressures were calcu-

\footnotetext{
${ }^{3}$ The saturation vapor pressure of a liquid substance in the presence of an inert gas differs from that when the pure substance alone is present. The factor $f_{w}$ accounts for this difference. It is defined as $f_{w}\left(P, T_{v}\right)=\frac{X_{r} P}{e_{2}}$. vapor-gas mixture under saturation at temperature $T_{w}$ and total absolute pressure $P$.
}

lated from the following equation given by Hildebrand [36]:

$e_{w}=$ Antilog $\left[6.89406-\frac{1219.58}{227.16+T_{w}}\right] \mathrm{mm} \mathrm{Hg}$

or

$e_{w}=0.0013332$ Antilog $\left[6.89406-\frac{1219.58}{227.16+T_{w}}\right]$ bars.

The estimated errors in these parameters are given in table 2.

Carbon Tetrachloride-Hydrogen System. Enthalpies were obtained as in the water-hydrogen system and all other parameters were obtained as in the carbon tetrachloride-oxygen system. The estimated errors in these parameters are given in table 2 .

Toluene-Air System. $h(P, T, 0)$ and $h\left(P, T_{w}, 0\right)$ were obtained for vapor-free air by linear interpolation of tabulated values given by Hilsenrath [33]. Values of $e_{w}$ were obtained from the equation of Rossini [37]:

$e_{w}=$ Antilog $\left[6.95464-\frac{1344.800}{219.482+T_{w}}\right] \mathrm{mm} \mathrm{Hg}$

or

$e_{w}=0.0013332$ Antilog $\left[6.95464-\frac{1344.800}{219.482+T_{w}}\right]$ bars.

A value of unity was assigned to $f_{w}$ and $L_{v}^{\prime}$ was computed from the equation given by Scott [38]:

$$
L_{v}^{\prime}=\frac{11637-4.823 T_{w}-1.260 \times 10^{-2} T_{w}^{2}}{92.141}
$$

where $T_{w}$ is given in degrees Kelvin. According to Scott, this formula is applicable over the temperature range of 298 to $410{ }^{\circ} \mathrm{K}$. However, since it was used to extrapolate values of $L_{v}^{\prime}$ at $280{ }^{\circ} \mathrm{K}$, allowance for this fact was made in estimating the error in $L_{v}^{\prime}$. The estimated errors in these parameters are given in table 2 .

\section{References}

[1] Monteith, J. L., Error and Accuracy in Thermocouple Psychrometry, Proceedings of the Physical Society, B LXVII, 217 (1954).

[2] Bindon, H. H., A Critical Review of Tables and Charts Used in Psychrometry, Humidity and Moisture 1, 3 (Reinhold Publishing Corp., New York, 1965).

[3] Harrison, L. P., Some Fundamental Considerations Regarding Psychrometry, Humidity and Moisture 3, 71 (Reinhold Publishing Corp., New York, 1965).

[4] Wylie, R. G., Psychrometry, Report PA-4, Commonwealth of Australia, Commonwealth Scientific and Industrial Research Organization, National Standards Laboratory, Division of Physics, University Grounds, Sydney, Australia, July 1949.

[5] Ivory, J., On the hygrometer by evaporation, Philosophical Magazine 60, 81 (1822).

[6] August, E. F., Uber die Verdunstungskälte und deren Anwendung auf Hygrometrie, Ann. der Physik und Chemie 5, 69 (1825).

[7] Apjohn, J., Formula for inferring the dewpoint from indications of the wet-bulb hygrometer, Phil. Mag. 6, 182 (1835).

[8] Apjohn, J., On the theory of the moist bulb hygrometer, Trans. Roy. Irish Acad. 17, 275 (1837). 
[9] Whipple, F. J. W., The wet and dry bulb hygrometer: The relation to theory of the experimental researches of Awberry and Griffiths, Proc. Phys. Soc. London 45, 307 (1933).

[10] Carrier, W. H., Rational psychrometric formulae, Am. Soc. Mech. Engrs. Trans. 33, 1005 (1911).

[11] Arnold, J. H., The theory of the psychrometer. II. The effect of velocity, Physics 4, 334 (Sept. 1933).

[12] Sherwood, T. K. and Comings, E. W., On experimental study of the wet-bulb hygrometer, Trans. Am. Inst. Chem. Eng. 28, 88 (1932).

[13] Lewis, W. K., The evaporation of a liquid into a gas-a correction, Mech. Eng. J. 55, 567 (1933).

[14] Dropkin, D., The Deviation of the Actual Wet-Bulb Temperature from the Temperature of Adiabatic Saturation, Cornell University Engineering Experiment Station, Bulletin No. 23 (July 1936).

[15] Brun, E. and Lions, M., Sur la theorie generale du psychrometrie et sur une methode simple d'etude experimentale des lois de diffusion forcie, C.R.A.S. (Paris) 222, 1071 (1946).

[16] Kawata, S. and Omori Y., An investigation of thermocouple psychrometer I, J. Phys. Soc. Japan 8, No. 6, 768 (1953).

[17] Maxwell, J. C., Diffusion, Encyl. Brit. 9th Ed. VII, 218 (1877).

[18] Mieghem, J. Van, La Thermodynamique du Thermometre Mouille, Bull. Classe Sci. Acad. Roy. Belgi. Bruxilles 27, 85 (1941).

[19] Svennson, A., Verdunstung und Abkühlung oder Erwärmung in dem Laminaren Gasstrom von Konstanter Geschwindigkeit. Anwendung auf Assmansche Aspiration-psychrometer, Arkiv. f. Mat. Astron. och Physik. Stockholm, Hafte 4, 22A, 23 (1932).

[20] Threlkeld, J. L., Thermal Environmental Engineering, Prentice-Hall, Inc., Englewood Cliffs, N.J. (1962).

[21] Weber, S., Psychrometrets Teori, Dansk Videnskobernes Selsk, Mathem-fys. Medd 3, No. 19 (1921).

[22] Arnold, J. H., The theory of the psychrometer. I. The mechanism of evaporation, Physics 4, 255 (July 1933).

[23] Goff, J. A., Standardization of thermodynamic properties of moist air-final report of working subcommittee, International Joint Committee on Psychrometric Data, ASHVE Journal Section, Heating, Piping and Air Conditioning 55, $118 \cdot(1949)$.

[24] Goff, J. A., and Gratch, S., Thermal properties of moist,air, ASHVE Journal Section, Heating, Piping and Air Conditioning 51, 334 (June 1945).
[25] Carrier, W. H. and Lindsay, D. C., The temperature of evaporation of water into air, Trans. of Am. Soc. Mech. Eng. 46, 739 (1924).

[26] Harrison, L. P., Proposal for an Experimental Triple-tubed Adiabatic Saturator to Measure Thermodynamic Wet-Bulb Temperature as a Limit Approached During the Saturation Process, Humidity and Moisture 1, 33 (Reinhold Publishing Corp., New York, 1965).

[27] Lewis, W. K., The Evaporation of a Liquid into a Gas, Trans. Am. Soc. Mech. Engrs. 44, 325 (1922).

[28] Nanda, V. S. and Kapur, R. K., A note on the thermodynamics of the wet- and dry-bulb hygrometer, Indian J. Phys. 31, 391 (1948).

[29] Wentzel, J. D., An instrument for the measurement of the humidity of air, American Society of Heating, Refrigeration and Air Conditioning Engineers Journal 66, 67 (Nov. 1961).

[30] Harrison, L. P., Fundamental Concepts and Definitions, Humidity and Moisture 3, 3 (Reinhold Publishing Corp., New York, 1965).

[31] Smithsonian Meteorological Tables, Smithsonian Institution, W ashington, D.C. (1951).

[32] Goff, J. A., Saturation Pressure of Water on the New Kelvin Scale, Humidity and Moisture 3, 289 (Reinhold Publishing Corp., New York, 1965).

[33] Hilsenrath, J., et al., Tables of thermal properties of gases, NBS Circ. 564 (1955).

[34] Bain, R. W., Steam Tables, Department of Scientific and Industrial Research, National Engineering Laboratory, East Kilbride, Scotland (1964).

[35] International Critical Tables (McGraw-Hill Book Co., Inc., New York, N.Y., 1928).

[36] Hildenbrand, D. L. and McDonald, R. A. The Heat of vaporization and vapor pressure of carbontetrachloride; the entropy from calorimetric data, J. Phys. Chem. 63, 1521 (1959).

[37] Rossini, F. D., et al., Values of Physical and Thermodynamic Properties of Hydrocarbons and Related Compounds (Carnegie Press, Pittsburgh, Pa., 1953).

[38] Scott, D. W., et al., Toluene thermodynamic properties, molecular vibrations and internal rotation, J. Phys. Chem. 66, 911 (1962).

(Paper 72C1-267) 